\title{
On complexity and variability of individuals' discretionary activities
}

\author{
Dimas B. E. Dharmowijoyo ${ }^{1}$ (D) Yusak O. Susilo $^{2}$ • \\ Anders Karlström²
}

Published online: 30 August 2016

(C) The Author(s) 2016. This article is published with open access at Springerlink.com

\begin{abstract}
Using a hierarchical structured equation model and a multi-dimensional 3-week household time-use and activity diary conducted in Bandung Metropolitan Area, Indonesia, this study investigated the interaction among individuals' non-instrumental variables, time space (such as their day-to-day time duration of activity participation, socio-demographics and built environment), and health factors on individuals' day-to-day discretionary activities. The results show that individuals' subjective characteristics and day-to-day time-space components significantly influence decision making processes to participate in certain activities, particularly grocery shopping. Integration between subjective factors and day-to-day time duration of activity participation also reveals how an individual categorises a particular behaviour as routine, planned or impulsive. For example, grocery shopping is a planned behaviour with real consequences (e.g. starving). Appearing as a strong commitment and intention enables individuals to allocate time to engage in this activity. Thus, given the individual's time-space constraints, there may be a regular tradeoff between frequency and duration. On the other hand, out-of-home social-recreational activity is a less urgent/impulsive activity and depends far more on an individual's day-today time-space constraints than his/her subjective characteristics. If the situation on the given day is not feasible for him/her to undertake the out-of-home social recreational activity, he/she is more likely to re-schedule the activity. The study results also show that
\end{abstract}

Dimas B. E. Dharmowijoyo dbedh@kth.se

$\triangle$ Yusak O. Susilo yusak.susilo@abe.kth.se

$凶$ Anders Karlström anders.karlstrom@abe.kth.se

1 Department of Civil Engineering, Institute of Technology and Science Bandung, Jalan Ganesha Boulevard Lot-A1, CBD Kota Deltamas Tol Jakarta-Cikampek Km 37, Cikarang Pusat, Bekasi, Indonesia

2 Department of Transport Science, KTH Royal Institute of Technology, Teknikringen 10, 10044 Stockholm, Sweden 
land use configuration and perceived accessibilities influence individuals' discretionary activity participation.

Keywords Day-to-day time-space constraints · Non-instrumental factors · Discretionary activities duration $\cdot$ Bandung Metropolitan Area $\cdot$ Indonesia

\section{Introduction}

In engaging with their daily activity-travel, travellers' needs and constraints are influenced by their personal and household socio-demographic characteristics and their socio-environmental conditions. Based on individual personal and social characteristics, Hägerstrand (1970) argued that an individual is subject to three types of constraints: capability constraints, coupling constraints, and authority constraints. These constraints interact with each other and define one's daily time-space prism. The conditions and variability of other resources, such as availability and service level of the infrastructure and public transport network, the selection of possible activity locations within reachable distances, access to various travel modes, and amount of money to spend, would provide individuals with opportunities to engage in more/less activities with more/less dispersed location and time. Given that individuals' needs, desires, and constraints differ from day to day, their timespace prisms and paths also differ from day to day (Schlich and Axhausen 2003; Miller 2005; Chikaraishi et al. 2011; Raux et al. 2012; Moiseeva et al. 2014; Susilo and Axhausen 2014). This complex mechanism means that each individual is unique and failing to accommodate these interactions biases analyses and predictions.

The constraints are not solely physical and instrumental factors, such as travel mode availability, time and cost. Non-instrumental variables such as motivation, volition and habits also come into play. Currently there is a lack of knowledge of how these noninstrumental variables are interacting and influencing the constraints that shape the individuals' travel behaviour (Lewin 1936; Weick 1976; McDonald 1994; Golledge and Stimson 1997; Dijst et al. 2008; Van Acker et al. 2011). Recent studies have hinted that different social and geographical conditions may present different sets of pressures and opportunities to the individual that correlate and differently interact with different individuals' subjective characteristics (McDonald 1994; Gärling and Axhausen 2003; Dijst et al. 2008; Dharmowijoyo et al. 2015b). Previous studies revealed that individuals' social and geographical conditions, including their activity locations and spatial movement patterns, are also influenced by non-instrumental factors, such as behavioural desire, volition, and past behaviour (Dijst et al. 2008; Dharmowijoyo et al. 2015b). Thus, individuals' temporal-social situations and trip engagements are correlated with that individual's noninstrumental factors. Given that each day is distinct, the influence of individual motivation, volitional state, and past behaviour on the variability of activity-travel behaviour may be different for different days.

Furthermore, any health or emotional problems may also influence individuals' activitytravel behaviour. How individuals' health condition influences their activity and travel participation may be more straightforward compared with the other way around (Dharmowijoyo et al. 2015b, 2016a). This highlights the importance of understanding the complex interdependencies between ones' health condition and ones' time-use and activity participation. 
The interactions between needs and constraints highlight that some activities (such as work/school and drop-off/pick-up child/children) are temporally and spatially fixed, while other activities, such as maintenance and leisure, are flexible/discretionary. The former are defined as mandatory and difficult to be re-scheduled, thus, dictating the individuals' ability to perform the latter. In this open information era, individuals' desire to connect with other people may increase travel distance and space exploration by utilising the recent advancements in vehicle technologies and infrastructure expansion, but may reduce them in terms of spending more time on certain activity types with other people (Axhausen 2006; Carrasco and Miller 2006, 2009). It is notable that discretionary activity trips (consisting of grocery shopping and social-recreation trips) tend to dominate individuals' trip making purposes (around 54-70\%, around half for social-recreation trips) rather than work/school trips (around 18-36 \%) in developed countries (Stauffacher et al. 2005). Grocery shopping and out-of-home social-recreation activities are the most important outof-home discretionary activities which tend to have different purposes in satisfying individuals' needs (Akar et al. 2011), and temporal and spatial fixity degree (Schwanen et al. 2008). Grocery shopping aims to satisfy individuals' biological needs and tend to have lower spatial and temporal fixity degree than out-of-home social-recreation in developed country case, whilst social-recreation trips fulfil cultural and physiological needs and tend to have more fixed spatial and temporal fixity degree. Understanding how different mechanisms underlie those different activities will help us to provide more opportunities for undertaking those activities and/or to manage trips related with those activities. Moreover, relating those activities with health parameters shows that undertaking socialrecreational activities tends to positively correlate with better social health conditions (Suzukamo et al. 2011; Dharmowijoyo et al. 2015b; Susilo and Liu 2016). Meanwhile, simultaneously undertaking grocery shopping as a primary activity and socialising as a secondary purpose, encourages individuals to do more physical activities, subsequently improving their physical health condition (Dharmowijoyo et al. 2015b).

While studies have investigated the complexity of discretionary activity participation (e.g. Yamamoto and Kitamura 1999; Joh et al. 2002; Pendyala and Yamamoto 2002; Meloni et al. 2004; Lee and Hickman 2007; Cirillo and Axhausen 2010), including how it was arranged between different household members and varied across different days (e.g. Kang et al. 2009; Kang and Scott 2010; Dharmowijoyo et al. 2016a), the interaction between individuals' day-to-day time-space components, his/her subjective characteristics and health factors in discretionary activity participation are largely unknown. In this study, it is hypothesised that integration among time-space, psychological and health components can categorise the level of priority of certain activities. Cullen and Godson (1975), Cullen (1978), and Golledge and Stimson (1997) have argued that classification of certain activities as a planned or an impulsive behaviour can be caused by integration between time-space and psychological factors. Moreover, time-space components such as daily time allocation to activity participation, socio-demographic and built environment variables are assumed to affect individuals' non-instrumental factors. Lastly, it is also hypothesised that incorporating health factors in the model will show how individuals' health constraints influence individuals' activity-travel behaviours. The interaction between health and time-space components may help us in coordinating health and timeuse policies,

All of the discussions above try to analyse individuals' behaviours in relation with their personal factors and associations with other individuals, materials and authorities' rules/ norms in multi-hierarchies and multi-dimensional perspectives within time-space limitations. The investigation tries to capture the complexity of interactions at the smallest level 
(Golledge and Stimson 1997; Marion 1999; Urry 2005; Ramalingam et al. 2008). Individuals' behaviours can be seen as individuals' efforts to satisfy their needs and desires in considering the interactions of multi-dimensional systems embedded within themselves under given time and space limitations. Integrating multi-dimensional perspectives can provide insight into the reasons why an individual performs certain activities/trips which may not be obviously captured by a one discipline approach (Dijst et al. 2009).

Using a 3-week household time-use and activity diary, this paper examined the relationship between individuals' non-instrumental variables (such as motivation, volition, and past behaviour), time-space and health factors on individuals' day-to-day grocery shopping and social-recreation activities. Time space components in this study were represented by day-to-day time duration of activity participation, socio-demographic and built environment variables. Those time-space components were available variables in this paper which explain time-space constraints. A hierarchical Structural Equation Model (SEM) was applied to take day-to-day variability effects into account, which examine the relationships between individuals' discretionary activity time and non-instrumental factors, such as behavioural desire, volition, and past behaviour.

In the next section, the datasets and variable specifications will be described. "Day-today variability in individuals' grocery shopping and out-of-home leisure activities" section presents the descriptive analyses of individuals' day-to-day variability in discretionary activity participation during the observed period. "Proposed model structure" and "Estimation results" sections describe the proposed model structure and model estimation results, respectively. Conclusions are presented in "Conclusions and discussion" section.

\section{The 2013 Bandung Metropolitan Area dataset}

\section{The Bandung Metropolitan Area}

The Bandung Metropolitan Area (BMA) is the capital of the Province of West Java and is approximately $200 \mathrm{~km}$ or 2-3 h' drive south of Jakarta. The BMA is located in a river basin, surrounded by volcanoes, in the central mountainous plateau region of West Java Province and is $700 \mathrm{~m}$ above sea level. Bandung was founded as a city in the seventeenth century and designed for 300,000 residents. Currently, it has around 2.5 million people just in the inner areas. With its conurbations, it encompasses around 7.89 million people, $3382.89 \mathrm{~km}^{2}$, and is the second largest metropolitan area in Indonesia after the Jakarta Metropolitan Area (JMA).

Compared to cities in developed countries, the BMA has a very relaxed or unplanned mixed and monocentric land use, congested road networks, and poor public transport networks and services (Susilo et al. 2010). Road congestion and low performance of public transport encourage the BMA's travellers to use motorcycles to reduce their travel costs and time (Susilo et al. 2015). At the same time, they usually have more choices within a closer range in which to conduct their activities along their travel routes, due to the highly mixed land use configurations. These conditions influence the size, spread, orientation, and variability of daily activity spaces (Dharmowijoyo et al. 2014). Unlike Jakarta, the BMA does not have a formal transit system. An infrequent one-line railway operation serves Cimahi in the West of Bandung City and Cileunyi in the East, which contributes only a marginal riding share. The majority of public transport operations are supported by indigenous public transport systems (called angkot and ojeg) that run like paratransit 
systems (Susilo 2011). They do not have particular stops, meaning they can stop everywhere. Most of these paratransit systems operate near the city centre; ojeg serves suburban or settlement areas where angkots do not operate (Joewono and Kubota 2007a, b; Tarigan et al. 2014).

\section{The 2013 BMA dataset}

The BMA dataset includes multi-dimensional information such as household, physical activity and lifestyle, individual's subjective characteristics, time-use and activity diary, and subjective well-being data. The dataset raises possibilities to analyse individuals' behaviour in multi-dimensional perspectives. Moreover, the interrelation among multidimensional perspectives and among time-space constraints reveals some endogeneity problems that exist due to the complexity of individuals' decision making processes.

The survey involved 732 individuals and 191 households from all over BMA for 21 consecutive days. The questionnaires were applied in Bahasa Indonesia as the native language of people in Indonesia. Due to poor registration of residents in Indonesia and other developing countries, the recruitment process started with direct interaction between surveyors and potential respondents, mediated by community leaders in selected neighbourhoods. Therefore, in the recruitment process, the survey did not have any response rate information. After the interaction, the respondents were asked to sign a commitment letter agreeing not to withdraw from the survey until it was completed. After signing the agreement, the surveyors began to distribute the questionnaires to the respondents. This process minimised the attrition of respondents in completing the survey. In this survey, none of respondents quit in the middle of survey time.

The household data section contained household composition, individuals' perception about how far his/her accommodation was from the city centre, public and transportation facilities, and built environment variables. The subjective perception of accessibility was used in this dataset, rather than objective measurements, because the traffic conditions in BMA, like in other developing cities, are rather unpredictable and are frequently highly congested. Thus, a subjective perceived accessibility was considered as a better measurement to capture the accessibility to various activity locations available from individuals' residential locations. The profile of the samples used in this study is illustrated in Table 1.

The time-use and activity diary survey captured twenty-three in-home and out-of-home activity classifications, travel duration and mode characteristics, and multitasking activities for adults, young adults and children above 7 years of age. In this study, time-use activity participation was classified into groups of mandatory and discretionary activities. The mandatory activities are classified as activities that are difficult to be re-scheduled (Cullen and Godson 1975) with relative higher temporal and spatial fixity (such as working, school and pick up/drop activities, Schwanen et al. 2008), thus, dictating the individual's ability to perform the discretionary activities. Moreover, discretionary activities are defined as activities that are easy to be re-scheduled within time and space limitations (Cullen and Godson 1975) with relative higher temporal and spatial flexibility such as grocery shopping and leisure activities (Schwanen et al. 2008).

Mandatory activities contained in-home and out-of-home mandatory activities. Out-ofhome mandatory activities were defined as activities to meet other individuals or materials at a location outside the home base such as working at workplace locations, studying at school, having business meetings and dropping off/picking up children to/from school 
Table 1 Profile of the samples used in the study

\begin{tabular}{ll}
\hline Variables & Percentage or mean \\
\hline
\end{tabular}

Socio-demographic characteristics at individual level

Male

Worker and non-worker

Is a dependent children ( $\leq 14$ years old)

Age (continuous) (years old)

Part of low income (<IDR 3 million/month) and medium income households

(IDR 3-6 million/month)

Household characteristics

Number of household members

Number of dependent children per household

Number of motorised vehicles per household

Reside within the inner city boundary of BMA and within Greater BMA

Trips engagements and travel time spent on weekdays (weekends) ${ }^{\mathrm{b}}$

Number of trips

Number of trip chains

Percentage of using motorised mode

Percentage of using public transport

Percentage of using non-motorised mode

Total travel time spent from Monday to Friday (min)

Time spent for different activities on weekdays (weekends) ${ }^{\mathrm{b}}$

Time spent for in-home mandatory activities (min)

Time spent for in-home leisure and maintenance activities (min)

Time spent for working/school activities (min)

Time spent for out-of-home grocery shopping (min)

Time spent for out-of-home social-recreational (min)

44.90 and $37.90 \%^{\mathrm{a}}$

$2.64(2.29)$

1.26 (1.08)

$39.19 \%(36.77 \%)$

$14.88 \%(9.55 \%)$

$34.49 \%(32.08 \%)$

74.87 (69.35)

693.17 (738.18)

308.23 (363.09)

298.85 (161.99)

13.11 (21.62)

$51.72(61.52)$

5.04 (24.75)

Time spent for out-of-home other maintenance and sport (min)

weekdays (weekends) ${ }^{\mathrm{b}}$

Percentage of time engaging with multi-tasking activities within travel activities $6.89 \%(5.22 \%)$

Percentage of time engaging with multi-tasking activities within out-of-home

$7.11 \%(3.64 \%)$ mandatory activities

Percentage of time engaging with multi-tasking activities within out-of-home

$17.84 \%(11.85 \%)$ discretionary activities

Built environment variables ${ }^{\mathrm{c}}$

$\mathrm{Km}$-length of road and railway per square-km within the respondents' residential location

Density of industrial and trade centre area per square-km within the respondents' residential location

Density of government office and settlement area ${ }^{\mathrm{d}}$ per square-km within the respondents' residential location

38.57 and 4.83

0.0244 and 0.0048

0.0120 and 0.4836

Perceived accessibility variables

Perceived number of public transport lanes passing respondent's resident

Perceived travel time to CBD and shopping centre area (min)

31.27 and 15.85

Perceived travel time to grocery store and park (min)

8.34 and 18.29 
Table 1 continued

Variables

Percentage or mean

Perceived travel time to the nearest place to stop public transport (min)

Trip chain is defined as home to home trip

a The remaining is students $(25.31 \%)$, part of high income households $(8.90 \%)$ and reside within CBD of BMA $(17.20 \%)$

b The values in brackets show the percentage/mean values on weekends, otherwise is on weekdays

c The density is calculated based on built area in only horizontal plane in $\mathrm{km}^{2}$ divided by total area in $\mathrm{km}^{2}$. The measurement is excluded the area on vertical plane

${ }^{d}$ Following the definition of density of certain built area, living in a denser settlement area does not always mean to live in a populated area. More populous area can mean an area which contains low density settlement area in horizontal plane (but denser in vertical plane)

locations. Activities that are undertaken at the home base for fulfilling the individual's basic needs such as sleeping, eating and personal care were defined as in-home mandatory.

Discretionary activities were separated into maintenance and leisure. Discretionary activities for satisfying household and personal physiological and biological needs (Akar et al. 2011) were defined as maintenance activities. These include in-home maintenance activities, such as housekeeping and nursing activities, as well as out-of-home maintenance activities such as grocery shopping, health treatment activities and other service activities (such as going to the bank, post office) (Kang and Scott 2010). For this study, out-of-home maintenance activities were separated into grocery shopping and other out-of-home maintenance. Moreover, leisure activities were discretionary activities undertaken within an individual's available time either in-home or out-of-home for satisfying cultural and physiological needs (Akar et al. 2011). These activities included entertainment (such as watching TV, listening to music/radio, reading magazines/newspapers and accessing the Internet), social and family activities (such as meeting with family members and friends, visiting relatives/friends and undertaking sport, leisure, and voluntary activities and going on holiday). Out-of-home meetings with other household members/relatives/friends and participating in out-of-home leisure, volunteer and going on holiday activities were defined as out-of-home social-recreation activities in this study. On the other hand, out-of-home sport was the only out-of-home leisure activity excluded from out-of-home social-recreational activities.

Multi-tasking activities were defined as concurrent activities which contained primary and secondary activities (Kenyon 2010; Circella et al. 2012) for satisfying different needs and desires at the same time. In this case, multi-tasking activities were defined as combining mandatory activities (such as work/school, eating, sleeping), maintenance activities (such as nursing, grocery shopping), and active leisure activities such as doing sport or reading a book with passive leisure activities, such as entertainment and socialising (Circella et al. 2012). Socialising in this case was defined as meeting with other people such as with other household members, or non-household members.

The questionnaire contained a section with health-related quality of life (QoL) questions and its potential influencing factors. Health-related QoL was developed based on SF-36 (Short-Form 36), one of the most widely used generic measures for health-related surveys. This set of questions has been adopted by more than 11 countries (Zhang 2013). It contains eight subscales that consider physical, social and mental health, which are measured in categories such as physical functioning (PF), limitations on role functioning according to 
physical health (RP), bodily pain (BP), general health (GH), mental health $(\mathrm{MH})$, limitations on role functioning due to emotional problems (RE), social functioning (SF) and vitality (VT). As suggested by Suzukamo et al. (2011), PF, RP and BP will be defined as physical health, RP, SF and RE as social health, and BP, GH, VT, SF, MH as mental health.

Subjective characteristics take in individual's planned behaviour, and habit. The Extended-Method of Goal Directed Behaviour (EMGB) theory was used in this study which also accounted how deliberation information precedes the actions or not. Actions preceded by deliberation processes (planned or reasoned behaviours) refer to the goal of the individual taking part in certain behaviours that appear after intention or planning (Gärling et al. 2001; Gärling and Axhausen 2003). In the Extended Model of Goal directed Behaviour (EMGB) theory, intention is formed by individuals' motivation which plays as the most proximal antecedents to influence individuals' intention. When the individual performs certain behaviours, he/she is being motivated to achieve that particular behaviour. Achieving a goal(s) is a necessary motivational function of decision-making (Thomson et al. 2009). Therefore, behaviour desire is applied to represent motivation which directly influences intention. The behaviour desire also includes attitude, subjective norms, perceived behaviour control $(P B C)$ and anticipated emotions as antecedents assumed to indirectly influence intention. Perugini and Conner (2000), Perugini and Bagozzi (2001) and Dharmowijoyo et al. (2015b) can be read to explain the theory in more detail. Only 584 respondents out of 732 were taken in this survey all of which were included in the analysis. There was no cleaning/filtering step in the analysis. The subjective questions used in this study are shown in Table 2.

\section{Day-to-day variability in individuals' grocery shopping and out-of-home leisure activities}

Figure 1a-d show the average day-to-day time spent in grocery shopping and out-of-home social-recreational activities, broken down by respondents' psychological factors, time allocations for out-of-home and in-home activities, and density of settlement area $/ \mathrm{km}^{2}$ within home zones variables. It can be seen that individuals' time allocation to both activity types varies daily and tends to reach the longest duration on Sunday. Presumably, this is because Sunday is the only full holiday in Indonesia (Dharmowijoyo et al. 2016a). On Sunday, individuals tend to have different activity-travel patterns from weekdays and longer duration for discretionary activities (Dharmowijoyo et al. 2016b).

People with strong motivation, commitment, intention, and a high frequency in the past to do grocery shopping and out-of-home social-recreation, tend to have shorter grocery shopping and social-recreation time duration, respectively. Moreover, individuals with longer in-home maintenance and shorter working/school time duration, and lower number of trips, tend to have longer grocery shopping duration. As seen in Fig. 1c, individuals with a strong motivation, commitment and intention, and higher frequency in the past to undertake out-of-home social-recreation tend to increase their participation in activities gradually from Monday to reach the highest level on Sunday. The pattern also looks similar for out-of-home social-recreational behaviour of individuals with longer in-home 
Table 2 Subjective characteristic questions used in the study

\begin{tabular}{lr}
\hline Questions & Mean \\
\hline $\begin{array}{l}\text { My desire to do out-of-home discretionary activities on weekdays within the } \\
\text { forthcoming week is (goal desire question) }\end{array}$ & $4.58(4.72)^{\mathrm{b}}$ \\
I think that to do grocery shopping ${ }^{\mathrm{a}}$ within the forthcoming weeks would be for me (attitude ques & $4.19(5.01)^{\mathrm{b}}$ \\
$1=$ unpleasant, $7=$ pleasant & $4.11(5.03)^{\mathrm{b}}$ \\
$1=$ unenjoyable, $7=$ enjoyable & $4.15(5.08)^{\mathrm{b}}$ \\
$1=$ unattractive, $7=$ attractive &
\end{tabular}

People who are important to me think I should do grocery shopping ${ }^{\mathrm{a}}$ within the forthcoming weeks (subjective norm question)

$1=$ disagree, 7 = agree

People who are important to me support me doing grocery shopping ${ }^{\mathrm{a}}$ on the weekdays within the forthcoming weeks (subjective norm question)

$1=$ disagree, $7=$ agree

If I do grocery shopping ${ }^{\mathrm{a}}$ within the forthcoming weeks make me feel (anticipated emotions question)
$1=\operatorname{sad}, 7=$ glad
$4.25(5.08)^{\mathrm{b}}$
$1=$ dissatisfied, $7=$ satisfied
$4.18(5.02)^{\mathrm{b}}$
$1=$ nervous, $7=$ calm
$4.17(4.99)^{\mathrm{b}}$
$1=$ bored, $7=$ enthusiastic
$4.15(4.91)^{\mathrm{b}}$
$1=$ passive, $7=$ active
$4.25(4.98)^{\mathrm{b}}$

For me, doing grocery shopping ${ }^{\mathrm{a}}$ on the weekdays within the forthcoming weeks is (PBC question)

$$
1=\text { very difficult, } 7=\text { very easy } \quad 4.07(4.52)^{\mathrm{b}}
$$

I am confident doing grocery shopping ${ }^{\mathrm{a}}$ on the weekdays within the forthcoming weeks (PBC question)

$$
1=\text { disagree, } 7=\text { agree } \quad 4.08(4.61)^{\mathrm{b}}
$$

I want to do grocery shopping on the weekdays ${ }^{\mathrm{a}}$ within the forthcoming weeks (behaviour desire question)

$$
1=\text { weak, } 7 \text { = strong }
$$

My desire to do grocery shopping on the weekdays ${ }^{\mathrm{a}}$ within the forthcoming weeks is (behaviour desire question)

$$
1=\text { unlikely, } 7=\text { likely }
$$

I will invest time in doing grocery shopping activities on the weekdays ${ }^{\mathrm{a}}$ within the forthcoming weeks (behaviour volition question)

$$
1=\text { unlikely, } 7=\text { likely }
$$

I intend to do grocery shopping on the weekdays ${ }^{\mathrm{a}}$ within the forthcoming weeks (behaviour volition question)

$1=$ disagree, $7=$ agree

How often did you do grocery shopping on the weekdays ${ }^{\mathrm{a}}$ during the previous year? (past behaviour)

$$
1=\text { never, } 7 \text { = everyday } \quad 3.98(4.38)^{\mathrm{b}}
$$

a "Grocery shopping" was replaced by "social-recreation activities for the questions about social-recreation activities"

b The value in the bracket shows the value of non-instrumental factors of out-of-home social-recreation

maintenance time. In this case, there may be a link between day-to-day participation in inhome maintenance with individuals' subjective characteristics.

Those with longer working/school duration may spend fewer hours socializing with colleagues at lunch time or after/before working/school time. Perhaps, this is why those with longer working/school time tend to have slightly different out-of-home socialrecreational time duration compared to individuals with shorter working/school time. 

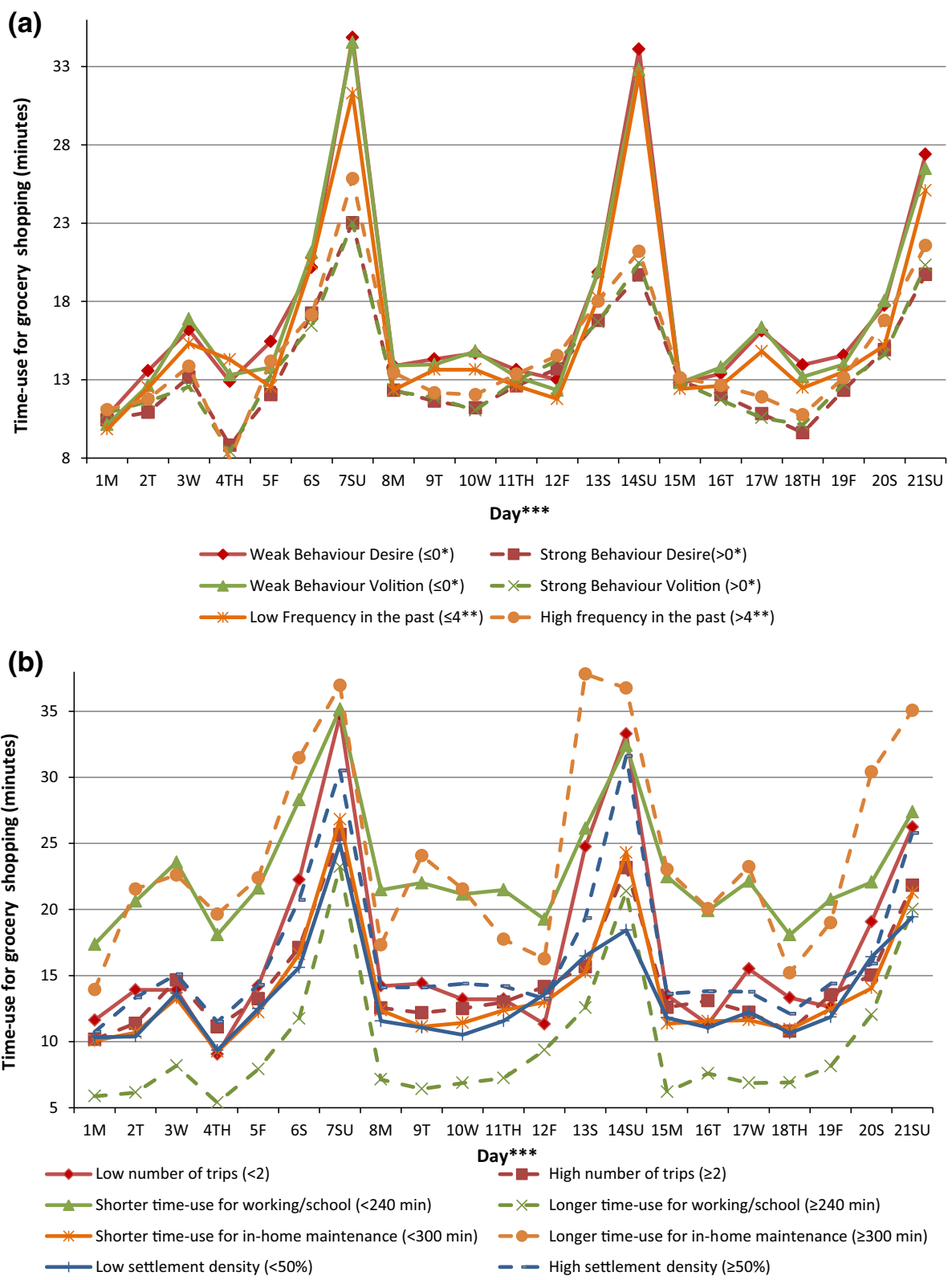

Furthermore, those with fewer trips and longer in-home maintenance time have the shortest duration for out-of-home social-recreation, but gradually increase this when approaching the weekends. There may be efforts to improve individuals' overall well-being (Baron 2005) or rating of good experience within their certain life episode (Rasouli and Timmermans 2014) by negotiating their time-use or day-to-day time allocation, meaning less stress and more freedom/relaxing/exciting activities (Anable and Gatersleben 2005). 
4Fig. 1 Day-to-day individuals' grocery shopping and out-of-home social-recreation. a Average time duration for grocery shopping by different levels of non-instrumental factors, b average time duration for grocery shopping by different levels of objective variables, $\mathbf{c}$ average time duration for out-of-home socialrecreation by different levels of non-instrumental factors, $\mathbf{d}$ average time duration for out-of-home socialrecreation by different levels of objective variables. ${ }^{*}$ These scores were obtained from factor scores of psychological variables that essentially carry the same information based on EMGB method in a more compact form. Higher positive scores show more favourable/easier stronger/more likely/positive anticipated emotions, whilst lower negative scores show less favourable/more difficult/weaker/less likely/negative anticipated emotions on each psychological related question shown in Table 2. **These variables were collected with possible answers shown in Table 2 using a seven item likert scale $(1=$ never to 7 = everyday). ***The survey started on Monday, 9th September 2013 (defined as Day 1M which means survey day 1 on Monday), to Sunday, 29th September 2013 (Day 21SU which means survey day 21 on Sunday). $M$ Monday, $T$ Tuesday, $W$ Wednesday, $T H$ Thursday, $F$ Friday, $S$ Saturday, $S U$ Sunday

Figure 1b, d show that individuals who reside in different densities of settlement area also tend to have different day-to-day amounts of time in both activity types. Figure $1 \mathrm{~b}$ illustrates that those from denser settlement areas tend to have longer grocery shopping time than those from low density ones. This may be because high density settlement areas tend to have closer access to grocery shops and other amenities (Handy et al. 2005; Susilo 2011; Arifwidodo 2012; Susilo et al. 2013) providing individuals with opportunities to spend more time on the activity.

As seen in Fig. 1a, c, having strong motivation, commitment and intention, and a high frequency in the past to engage in a particular activity does not necessarily make the individuals spend their time and trips engaging with that particular activity. Not all intentions and plans are materialized; they are subject to individuals' constraints on given time and space. At the same time, individuals like to retain patterns they are comfortable with, and their perceived ability and accessibility to reach and to engage in activities are not perfect (Susilo and Axhausen 2014; Heinen and Chatterjee 2015). Thus, understanding the interaction between individuals' subjective characteristics and their daily time-space constraints will give insight on how those variables influence each other on a daily basis.

\section{Proposed model structure}

To better understand the relationships between different subjective, temporal, social and spatial elements, the interaction between day-to-day time-space constraints and psychological mechanisms were modelled in this study. In social science research, hierarchical nesting observations (such as day-to-day variability effect) should be considered to better capture individuals' behaviour instead of mutual independent observations (Snijders and Bosker 1999; Schwanen et al. 2008). Moreover, day-to-day time-space factors were assumed also to affect individuals' motivational and volitional states, and their past behaviour (Dijst et al. 2008; Dharmowijoyo et al. 2015b) beyond the integrative functions of antecedents. Interaction with time-space factors might make some psychological antecedents found to insignificantly influence an individual's behavioural motivation and volition (Dijst et al. 2008). Built environment and perceived accessibility were also included in the analysis to show interaction with environment and individual perception toward environment (Paccione 2003).

Psychological mechanisms influence individuals' behaviour in a recursive way (Ajzen 1991; Perugini and Conner 2000; Dijst et al. 2008) and no reciprocal effect was assumed to influence structural forms of psychological mechanisms. Individuals' attitude, subjective norm, perceived behavioural control, goal desire, and anticipated emotions were assumed 
(c)

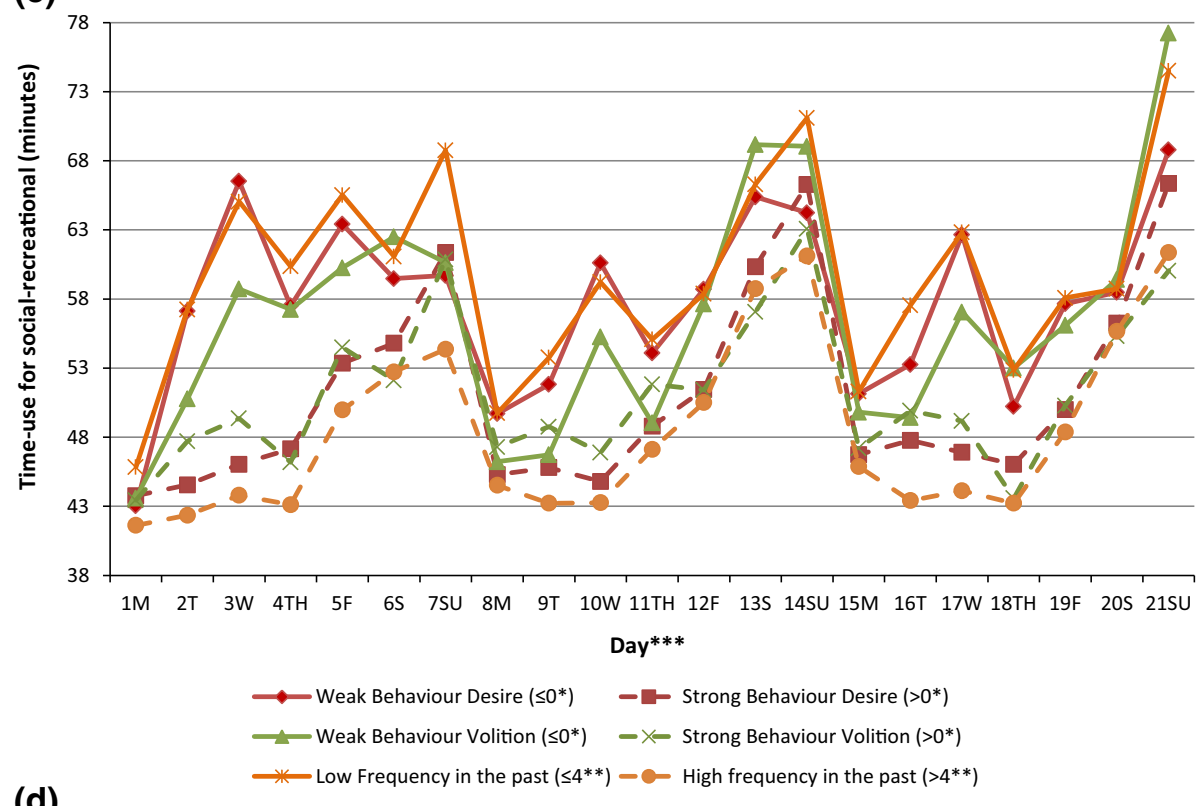

(d)

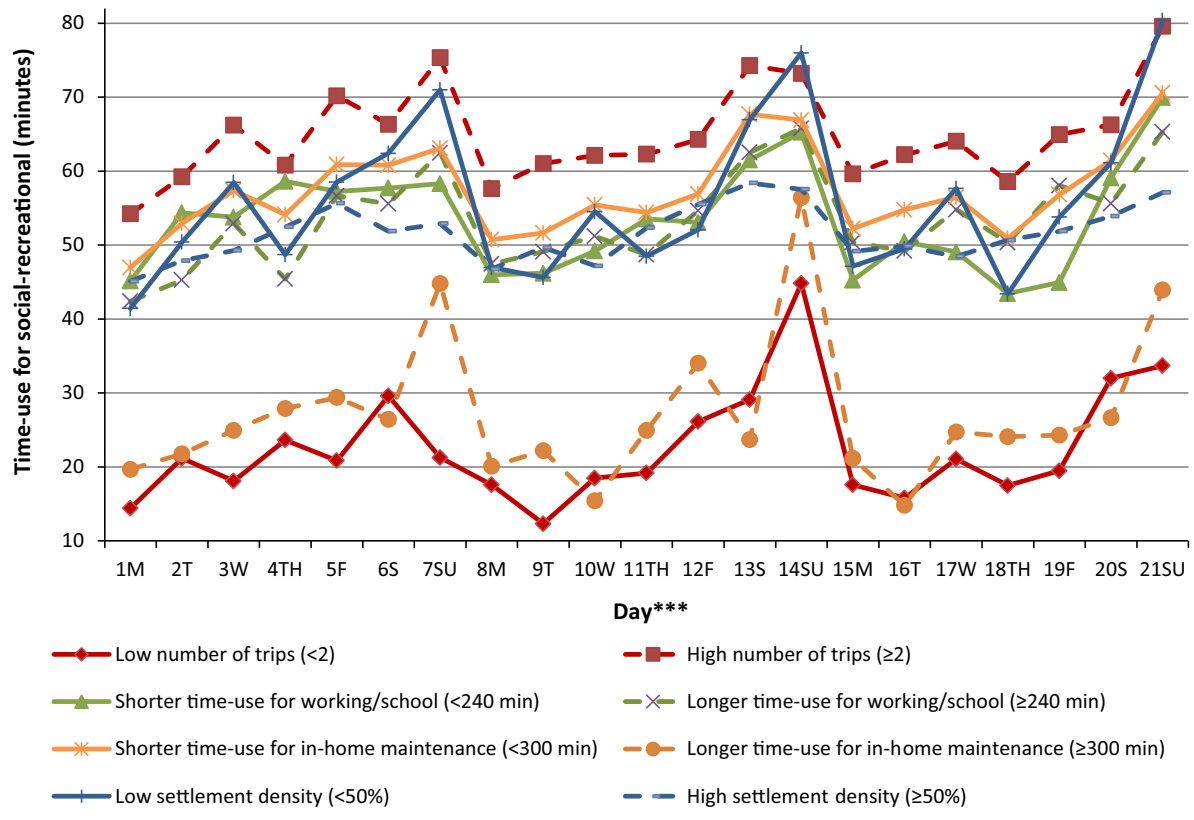

Fig. 1 continued

to influence their behavioural motivation as in influencing their commitment and intention (behavioural volition).

Due to the psychological factors' interaction, it is possible to explore the complex interaction between day-to-day time-space factors and the psychological mechanisms 


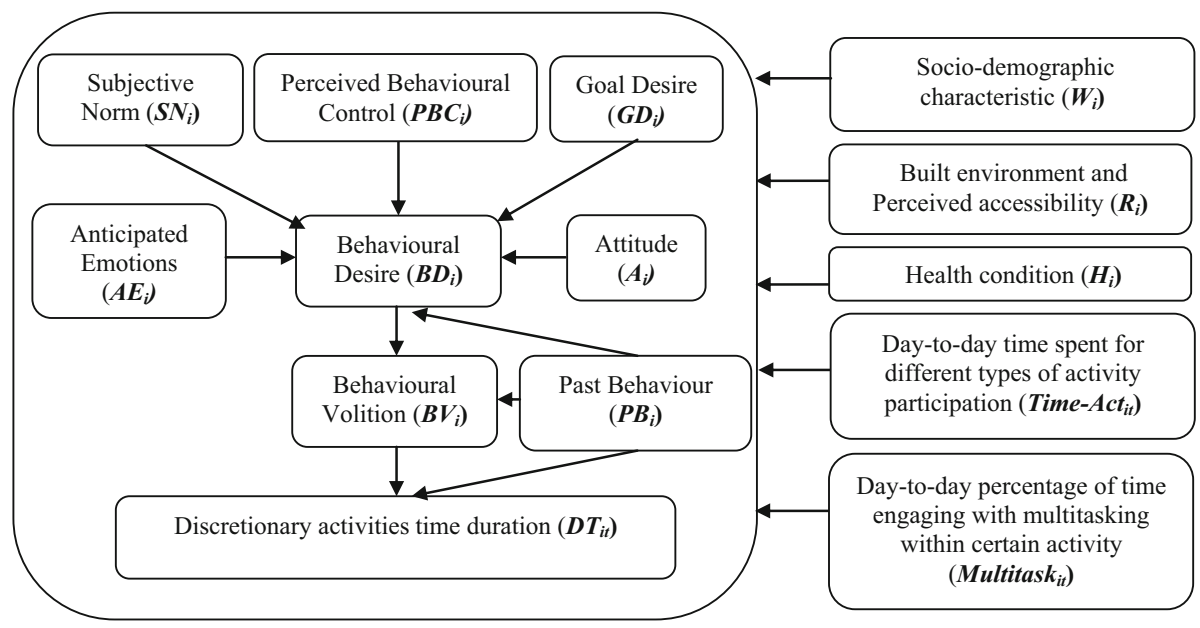

Fig. 2 The proposed model

using a hierarchical SEM (Dharmowijoyo et al. 2015a). A hierarchical SEM captured the complexity of psychological mechanisms in a recursive structure while accounting for the day-to-day variability effect of individuals' time-space constraints. The method was not expected to deal with any reciprocal effect in examining psychological factors' interaction. Each psychological factor was formed from observable indicators in the measurement model and its antecedent/s in structural form. In this study, factor scores showed the value of psychological factors from the observable indicators. Estimated psychological factors tended to account for their antecedents as well as the day-to-day variability of time use and activity participation, trip engagement, socio-demographic and geographical variables are shown in Fig. 2.

The coefficients of parameters $(\beta n$ and $\gamma n)$ in the hierarchical SEM took into account day-to-day variations in endogenous activity-travel patterns and exogenous variables made by individual $i$ on day $t$. The uncorrelated individual specific error term $\left(u_{n}\right.$, for $\left.n=1-4\right)$ has a mean value of zero and variance of $\sigma_{u}$, while $\varepsilon_{n}$ (for $n=1-4$ ) is the uncorrelated combined time and individual error components with a mean value of zero and variance of $\sigma_{\varepsilon}$. The individual specific error term captured the unobserved heterogeneity amongst individuals which was not explained by their day-to-day variations in activity-travel pattern variables. The coefficients of parameters $(\beta n$ and $\gamma n)$ were estimated by modified $O L S$ or generalised least square (GLS) (Gujarati 2003). GLS was selected to produce an uncorrelated estimation between individual specific error terms, and combined time and individual error components. The GLS also yields independent estimations between those error terms and endogenous and exogenous variables to produce unbiased, consistent, efficient and asymptotically normal estimations for this purpose (Gujarati 2003; Hansen 2004).

To more clearly show the model in Fig. 2 within mathematical forms, Eqs. 1-4 were written as follow:

$$
P B_{i}=\left(\alpha_{1}+u_{1}\right)+\beta_{1} W_{i}+\beta_{2} R_{i}+\beta_{3} H_{i}+\beta_{4}{\text { Time }- \text { Act }_{i . t}+\beta_{5} \text { Multitask }_{i . t}+\varepsilon_{1}}
$$




$$
\begin{aligned}
& B D_{i .}=\left(\alpha_{2}+u_{2}\right)+\beta_{6} A_{i}+\beta_{7} S N_{i}+\beta_{8} P B C_{i}+\beta_{9} A E_{i}+\beta_{10} G D_{i}+\beta_{11} W_{i}+\beta_{12} R_{i} \\
& +\beta_{13} H_{i}+\beta_{14} \text { Time } \text { Act } t_{\text {.t }}+\beta_{15} \text { Multitask }_{i . t}+\gamma_{1} \widehat{P B}_{i, t}+\varepsilon_{2}
\end{aligned}
$$

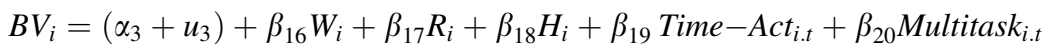

$$
\begin{aligned}
& +\gamma_{2} \widehat{B D_{i, t}}+\gamma_{3} \widehat{P B_{i, t}}+\varepsilon_{3}
\end{aligned}
$$

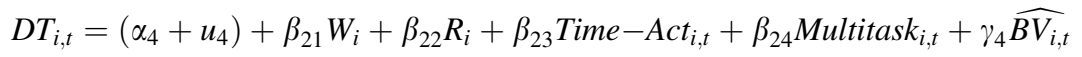

$$
\begin{aligned}
& +\gamma_{5} \widehat{P B_{i, t}}+\varepsilon_{4} \text {. }
\end{aligned}
$$

The coefficient parameters were estimated by maximum likelihood estimator as shown in Eq. 5 (Breusch 1987; Greene 1993) with LIMDEP version 8.0. From Eq. 5, N was defined as a matrix of cross-sectional units (e.g. individuals or firms) with $\mathrm{N}=1, \ldots, \mathrm{N}$, whilst $\mathrm{T}$ was defined as a matrix of time periods with $\mathrm{T}=1, \ldots, \mathrm{T}$. Moreover, $d=y-X \beta$, where $Q_{w}=I-P_{w}$ with $P_{w}=T^{-1}\left(I_{N} \otimes I_{T^{\prime}} I_{T^{\prime}}\right) . Q_{b}$ is $Q_{0}-Q_{w}$ with $Q_{0}=I-N T^{-1} l_{N T} l_{N T}^{\prime}$ and $\theta=\sigma^{2} /\left(\sigma^{2}+T \sigma_{\alpha}^{2}\right)$. Now, with Eq. 5, maximising over $\beta$ given $\theta$ yields:

$$
L^{*}(\beta, \theta)=-\frac{N T}{2} \log \left\{d^{\prime}\left(Q_{w}+\theta Q_{b}\right) d\right\}+\frac{N}{2} \log \theta
$$

Iterative GLS was used by successive Eqs. 6 and 7, starting from some initial values for $\beta$ in $d=y-X \beta$ in 7 or for $\theta$ in 6 .

$$
\beta_{M L E}=\left[X^{\prime}\left(Q_{w}+\theta Q_{b}\right) X\right]^{-1}\left[X^{\prime}\left(Q_{w}+\theta Q_{b}\right) y\right]
$$

and maximising over $\theta$, given $\beta$ yields:

$$
\theta=\frac{d^{\prime} Q_{w} d}{(T-1) d^{\prime} Q_{b} d}
$$

The advantage of this model compared to certain path analysis method (e.g. FIML) is that it can deal with categorical variables. Individuals' socio-demographic variables may be better explained by categorical instead of continuous variables due to the non-linear behaviours of the variables. The heterogeneity of non-instrumental factors may be explained by individuals' socio-demographic variables (Ajzen 1991; Anable 2005; Dijst et al. 2008; Dharmowijoyo et al. 2015b). Moreover, the model needs less computational time compared to multilevel path analysis models. However, it is inefficient when estimating the relationships between latent variables and hierarchical nesting observations.

\section{Estimation results}

Tables 3 and 4 show that participation in day-to-day discretionary activity behaviours are integrated between individuals' day-to-day social situation, geographical condition of the home zone, and subjective characteristics. Geographical condition was also found to significantly influence individuals' volitional and past behaviour to undertake both activities. Accounting for the day-to-day variability effect makes some psychological antecedents, such as attitude and anticipated emotions, not influence behavioural desire significantly. The salient results are shown below. 


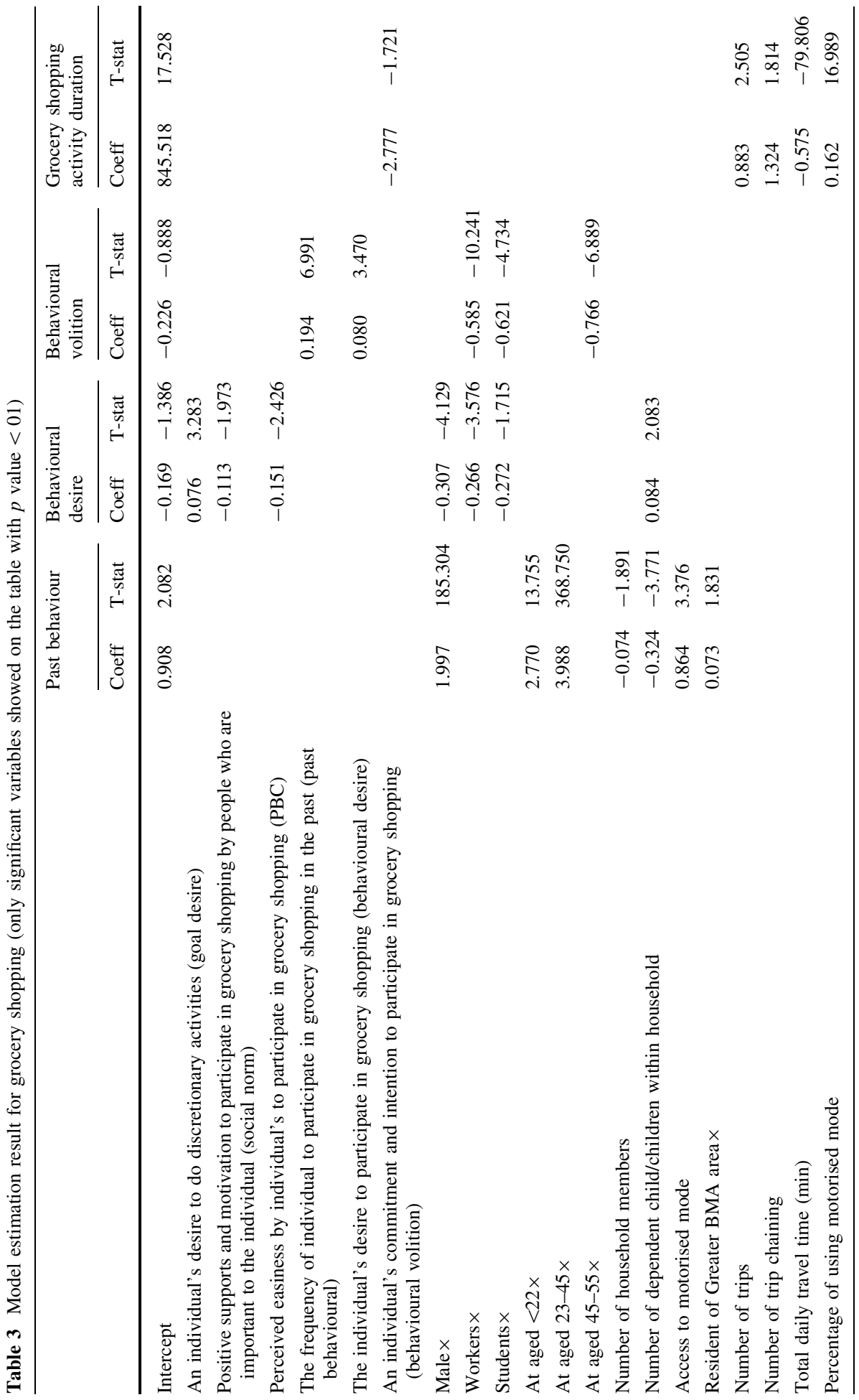




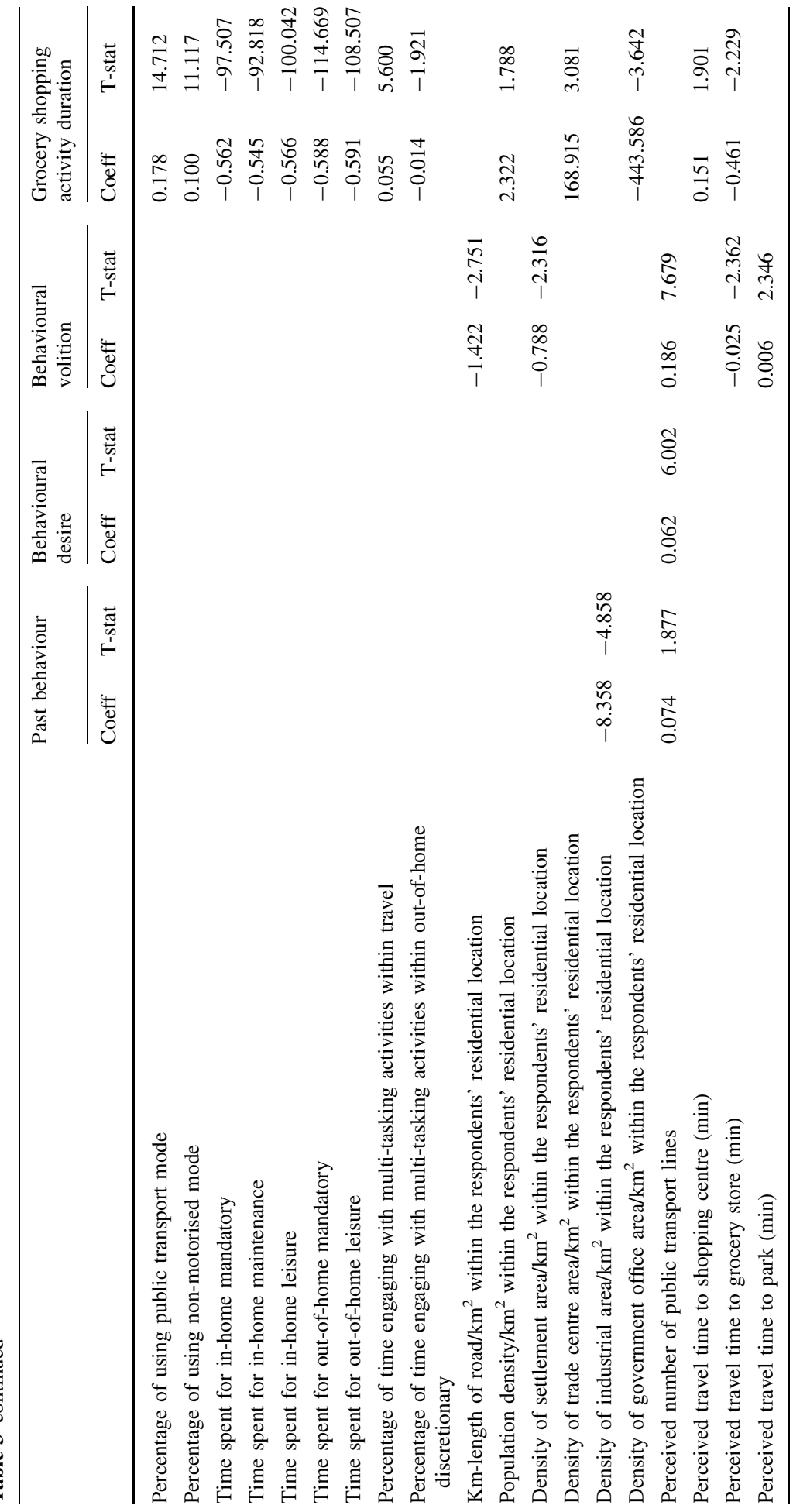




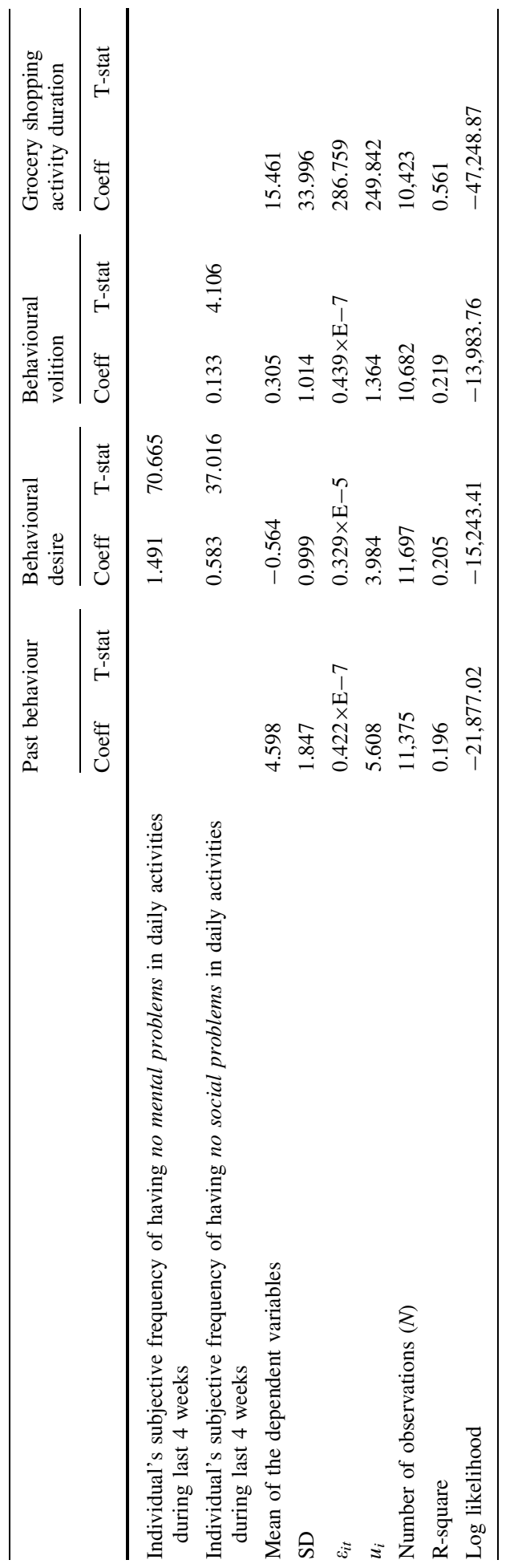




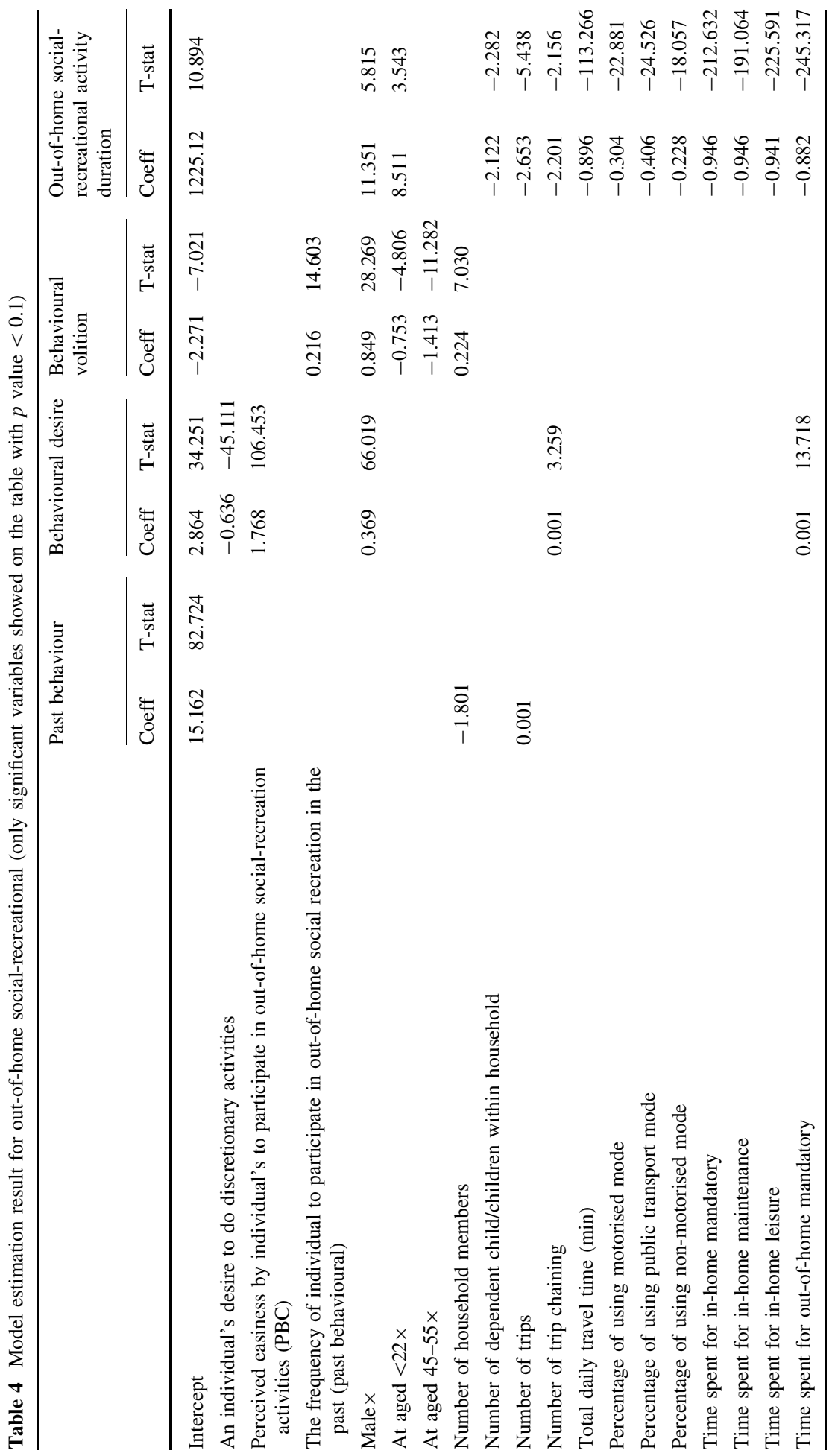




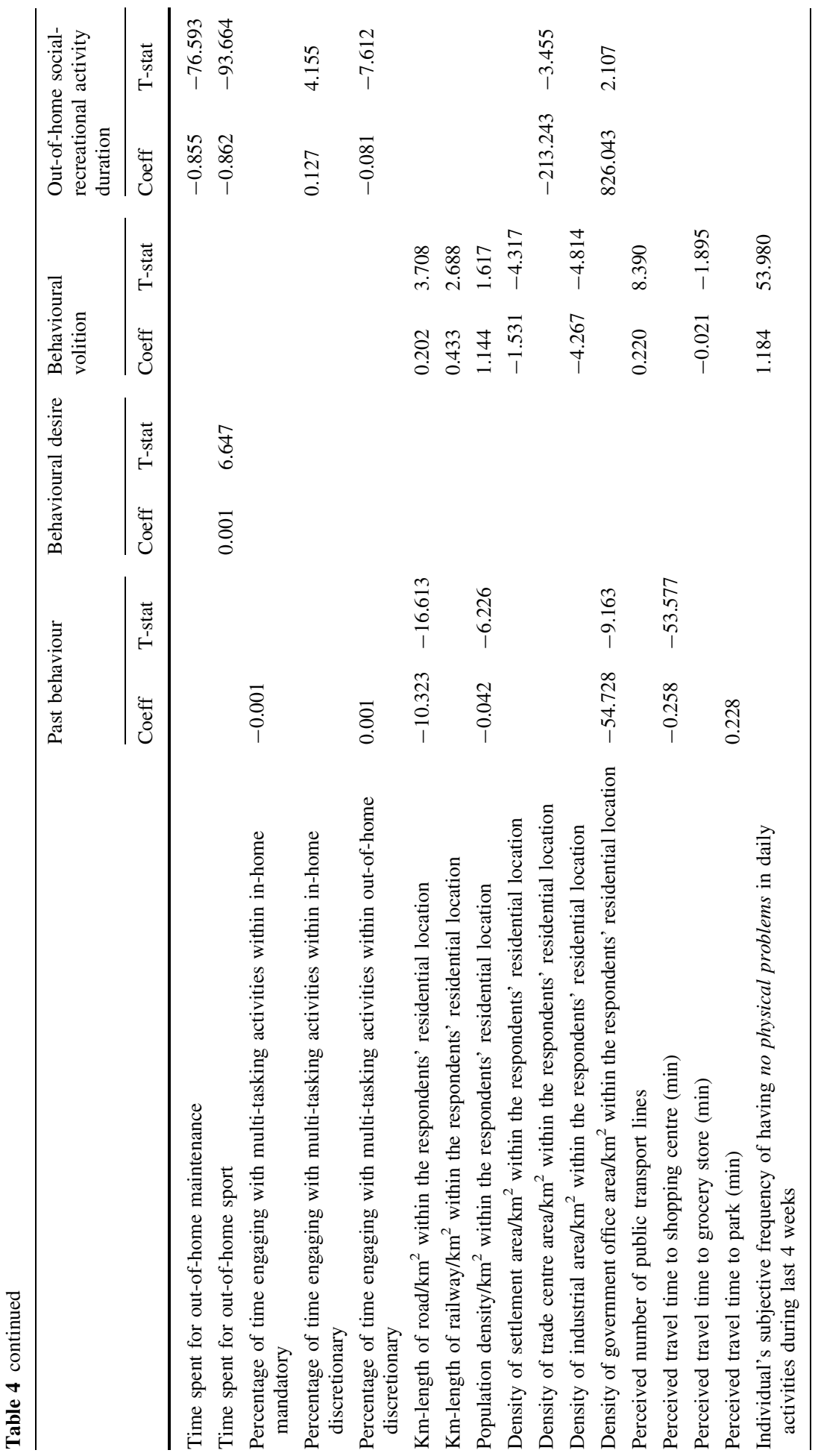




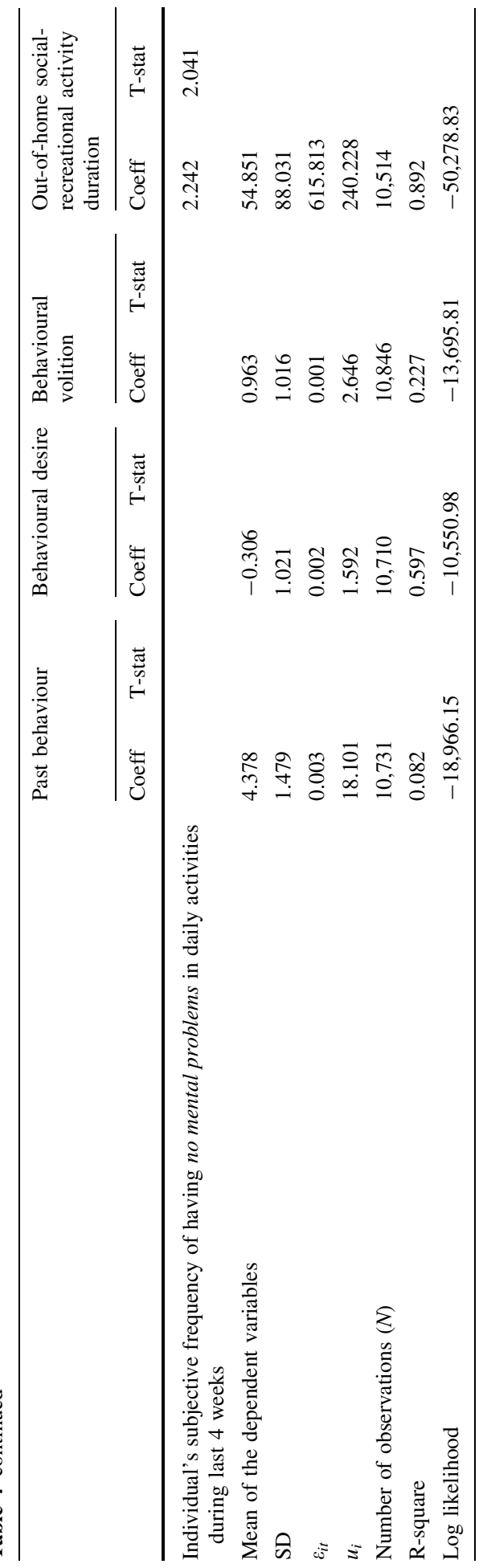




\section{Time use for grocery shopping activities}

The results illustrate that individuals' motivation, commitment, intention, and frequency in the past to engage in grocery shopping tend to be time invariant. Individuals' psychological factors are not influenced by the difference of day-to-day individuals' day-to-day social situations indicated by day-to-day time duration of activity participation. However, living within different geographical locations tends to explain individuals' volitional stage.

Those with better social and mental health tend to have stronger motivation to grocery shop, whilst having better social health tends to positively correlate with stronger commitment and intention to do the activity. Moreover, socio-demographic variables tend to also affect non-instrumental variables. For example, non-workers have stronger motivation, and commitment and intention to undertake grocery shopping, while females have stronger motivation, but lower frequency of the activity in the past. Students tend to have the lowest motivation, commitment and intention to grocery shop compared with workers and non-workers. In addition, having more household members and dependent children tends to reduce past frequency of grocery shopping, indicating intra-household activity sharing arrangements (Susilo and Axhausen 2014). At the same time, having access to motorised transport and residing within the Greater BMA Area positively correlates with a higher frequency of grocery shopping in the past.

As expected, behavioural volition is influenced by considerable situational variables than behavioural desire. Behavioural volition is a closer stage to actual behaviour than planning or motivation, thus, it is logically acceptable that situational variables in larger number are found to significantly affect behavioural volition. Having a shorter perceived travel time and more perceived public transport lines gives an individual higher commitment and intention to do the activity, whilst residing within a denser settlement area and longer roads $/ \mathrm{km}^{2}$ tends to show an opposite result. Having closer access to grocery shopping locations may make individuals who reside within denser settlement areas (Arifwidodo 2012; Tarigan et al. 2016) have less commitment and intention to do grocery shopping compared with those who have farther access to grocery shopping in less dense areas. Moreover, those who reside near the city centre with longer road $/ \mathrm{km}^{2}$ tend to be dominated by high income households who may have a home assistant to do grocery shopping on their behalf (Dharmowijoyo et al. 2015a, 2016a). On the other hand, residing close to a dense trade area makes individuals perceive having a shorter travel time to reach the grocery shops. At the same time, those residing in denser government office areas tend to perceive longer travel times to grocery shop locations.

Regarding close interaction between day-to-day variability effect and geographical constraints, it can be seen from Table 3 that a higher commitment and intention to engage in grocery shopping correlates negatively with grocery shopping duration. As highlighted by previous studies (e.g. Susilo et al. 2013), there is a trade-off between shopping frequency and duration, and with the quantity and type of grocery shopping. For top-up, routine grocery shopping, individuals do not need to spend long on the activity. Participating in work/school and out-of-home leisure activities has a higher impact in reducing the duration of grocery shopping compared to participation in inhome activities. This may be due to individuals' out-of-home time budget affecting the trade-off between different activities' duration and participation (Susilo and Avineri 2014; Ahmed and Stopher 2014). 


\section{Time use for out-of-home social and recreational activities}

Goal desire and perceived behavioural control, respectively, were found to negatively and positively correlate with individuals' motivation to undertake out-of-home social and recreational activities. As shown in the estimation results in Table 4, different to grocery shopping participation models, individuals tend to have different motivation to undertake out-of-home social-recreation on different days due to differing day-to-day social situations and trip engagement. Those with longer work/school and out-of-home sport time, and higher trip chains, tend to have a stronger motivation to do the activity.

However, the difference in social situation on different days does not influence individuals' behaviour volition. As shown in Table 4, commitment and intention to do out-ofhome social-recreation is relatively time invariant on the given days. Commitment and intention tends to be influenced by the geographic location of individuals' home, past behaviour, and general differences in social context between males and females, and senior citizens and their younger counterparts.

Individuals who reside within a more populated area (population density higher than 10,000 people $/ \mathrm{km}^{2}$ ), denser settlement and trade areas (above 55 and $2 \%$ of the areas are settlement and trade areas, respectively) tend to perceive a shorter travel time to the city centre (around $22 \mathrm{~min}$ ), while others perceive it to be $39 \mathrm{~min}$. However, controlling for the similarities/differences of population and settlement densities, and perceived average travel time to the city centre, those living in more populated areas tend to have different commitments and intentions to undertake out-of-home social-recreation to those living in denser settlement areas. A more populous area would also contain kampongs which may be resided in by more people within the same built area on a horizontal plane than real-estate or non-kampongs areas (McCarthy 2003). More populous areas may have a denser settlement area not only in the horizontal plane but also in the vertical plane (McCarthy 2003). Denser populated and mixed land use areas may contribute to the more populated areas compared to denser settlement areas in the studied location, which tend to have more formal and informal social contact via membership of religious organisations, civic engagement, and neighbourhood interaction (Putnam 2001). Moreover, individuals who reside in less populated areas with denser industry, tends to have a weaker commitment and intention to undertake the activity than those from an area with a higher length of road/ $\mathrm{km}^{2}$.

Different to the grocery shopping model, out-of-home social recreation activity duration was affected only by individuals' time-space components. No psychological factors were significant. A higher time allocation to in-home and out-of-home activities has a higher impact on reducing individuals' allocation to out-of-home social recreational activities than to grocery shopping activities. Individuals in a developing country may define the activity as more temporally flexible than grocery shopping (Dharmowijoyo et al. 2016a) in contrast to the results in a developed country (Schwanen et al. 2008). Not materialising an activity when having a strong commitment and intention to participate in the activity may show how individuals deprioritise the activity due to having tighter time-space constraints on a given day. Individuals who reside within dense government office areas tend to spend longer in out-of-home social and recreational activities than those who live in denser trade centre areas. 


\section{Conclusions and discussion}

Using a hierarchical SEM and a multi-dimensional 3-week household time-use and activity diary, this study investigated the interaction of day-to-day variability of individuals' activity time duration and trip engagements, built environment, socio-demographics with non-instrumental factors on their grocery shopping and out-of-home social-recreational activity participation. The estimation results showed that individual behaviour is a complex interaction between daily time-space and subjective factors.

The results illustrate that individuals' commitment and intention to do discretionary activities and motivation to undertake grocery shopping tends to be time invariant. It is not influenced by the difference of daily social situations represented by daily time allocation to activity engagement. Different groups of individuals with different social roles in general (Bird and Fremont 1991) tend to have a different commitment and intention to undertake those activities. In BMA area or in developing country cases in general, it is common that female and non-workers tend to have stronger motivation and volition to do grocery shopping than males and workers. Females are likely to be non-workers in developing country cases (Dharmowijoyo et al. 2014, 2015a, b). They have responsible to do grocery shopping when males who are likely to be workers, have responsible to work. Males and the ones from bigger households are also common to have stronger volition to undertake social-recreation activities than female and the ones from smaller households, respectively. Males tend to be workers who tend to have longer time allocation to work, whilst the ones with bigger households tend to have more time to do maintenance activities than smaller ones (Dharmowijoyo et al. 2015b, 2016a). However, individuals' motivation to engage in out-of-home social-recreational activities tends to vary on different days due to having different social situations on different days. As expected, the different geographical situations tend to determine the strength/weakness of an individual's commitment and intention to perform both discretionary activities.

Integration between subjective factors and day-to-day time duration of activity participation also reveals how individuals categorise a particular behaviour as a planned or impulsive behaviour. An activity is considered as a planned behaviour/prioritised behaviour when having a strong commitment and intention to participate in certain activity makes an individual tries to spare time to undertake the activity (Cullen and Godson 1975; Cullen 1978; Golledge and Stimson 1997). Otherwise, when an individual deliberately denies his/her strong commitment and intention to participate in the certain activity, thus make him/her does not spare time and/or chooses to re-schedule the given activity, it may be considered impulsive/lowly prioritised (Cullen and Godson 1975; Cullen 1978; Golledge and Stimson 1997). Understanding and accommodating activity prioritisation mechanisms and the influence of individual's non-instrumental variables towards them are important for travel demand analysis and policy design.

Based on above definitions, different types of discretionary activity were found to have different interaction patterns between individuals' daily time-space constraints and their psychological factors. Grocery shopping is a conscious activity with real consequences (e.g. starving) rather than a habit. While participation in this activity is also subject to individual time-space constraints, there is an indication of a trade-off between frequency and duration regarding activities performed daily as also shown in the descriptive analysis section. On the other hand, out-of-home social-recreational activity is a less urgent activity that depends far more on an individual's day-to-day time-space constraints than his/her subjective characteristics. These results show how different constraints in developing 
constraints makes individuals tend to have a different prioritisation degree on many discretionary activities from developed country cases. Individuals may have a strong commitment and intention to participate in out-of-home social-recreational activities (Anable and Gatersleben 2005) every day to improve their well-being (Baron 2005) or rating of good experiences within their certain life episodes (Rasouli and Timmermans 2014). However, if the situation on a given day was not feasible for them to undertake out-ofhome social-recreation activity, they were more likely to reschedule the activity.

Recording multi-tasking tends to reveal how undertaking socialising activities as secondary activity within out-of-home discretionary activities (as primary) makes individuals reduce their grocery shopping and/or out-of-home social-recreation time. It uncovers individuals' efforts to manage their participation in socialising activities within tighter time schedules in conjunction with other activities as primary (Kenyon and Lyons 2007; Sullivan and Gershuny 2012) in order to improve their well-being (Baron 2005) and/or rating of good experiences in a certain life episode (Rasouli and Timmermans 2014).

For policy implementation, ignoring either subjective factors or time-space components may underestimate whether certain policy implementation may be needed/may not be needed to provide more opportunities to undertake a particular behaviour. For example in grocery shopping case, because participation in grocery shopping is subject to individuals' commitment and intention to undertake such activity, and does not need a long time allocation (only $13 \mathrm{~min}$ in average for the ones with higher behaviour volition and $17 \mathrm{~min}$ in average for the counterpart) due to having accessible grocery shops in all areas of study (grocery shops can be reached within $8 \mathrm{~min}$ of travel time in average in all areas), implementation any time-use policies would not relatively influence increasing time allocation to such activity. Maintaining the density of grocery shops is still applicable policy in all type of areas in order to provide more accessible grocery shops particularly within congested city such as BMA or other developing country cities. However, unmanaged denser grocery shops can also raise traffic conflicts within a congested area as BMA or other developing country cities and shut down some grocery shops. On contrary, different from grocery shopping activities, time-use policies such as reducing time allocation to in-home activities and working are still relevant policies to provide more opportunities to allocate time for out-of-home social-recreation in developing country case. Suggesting a more balanced life policy with balanced time to undertake household activities, sleep, work/study, in-home and out-of-home activities (particularly out-of-home leisure or social/recreation) is also indicated in this study which tend to correspond with having better social and mental health in developed (Hunt et al. 2015) and developing country cases (Dharmowijoyo et al. 2015b, 2016b). Furthermore, this study also reveals that travel time reduction policies particularly for public transport will provide travellers who reside in sub urban and greater area with higher opportunities to undertake out-ofhome social-recreation activities. Locating sub urban and greater area with more reachable social-recreation activity destinations such as placing more parks or play grounds closer with individuals' residential locations may be able to provide more opportunities to undertake out-of-home social-recreation activities.

Excluding one multi-dimensional factor would miss individuals' complex decision making process in undertaking a particular behaviour as noted in the hypotheses above. Integrating time-space and subjective components would provide insight how individuals put priority level on a particular behaviour, thus will help us to suggest better strategies or policy implementations. This study also suggests solutions how we set our built environment which meet with individuals' efforts to satisfy their needs and desires. Moreover, the travel and activity commitments of individuals are also subject of intra-household's 
commitments and arrangements. The trade-off and altruism interactions between household members have not been taken into account in this study and are subject to future study. Furthermore, relating how undertaking the discretionary activities behaviour with health and/or well-being improvement efforts would also be the next possible step of the studies.

Acknowledgments This paper is part of a doctoral research funded by the Ministry of Education of Indonesia and the KTH Royal Institute of Technology.

Open Access This article is distributed under the terms of the Creative Commons Attribution 4.0 International License (http://creativecommons.org/licenses/by/4.0/), which permits unrestricted use, distribution, and reproduction in any medium, provided you give appropriate credit to the original author(s) and the source, provide a link to the Creative Commons license, and indicate if changes were made.

\section{References}

Ahmed, A., Stopher, P.: Seventy minutes plus or minus 10-a review of travel time budget studies. Transp. Rev. 34(5), 607-625 (2014)

Ajzen, I.: The theory of planned behaviour. Organ. Behav. Hum. Decis. Process. 50, 179-211 (1991)

Akar, G., Clifton, K.J., Doherty, S.T.: Discretionary activity location choice: in-home or out-of-home. Transportation 38, 101-122 (2011)

Anable, J.: 'Complacent car addicts' or 'aspiring environmentalistś identifying travel behaviour segments using attitude theory. Transp. Policy 12, 65-78 (2005)

Anable, J., Gatersleben, B.: All work and no play? the role of instrumental and affective factors in work and leisure journeys by different travel modes. Transp. Res. Part A 39, 163-181 (2005)

Arifwidodo, S.D.: Exploring the effect of compact development policy to urban quality of life in Bandung. City Cult. Soc. 3, 303-311 (2012)

Axhausen, K.W.: Activity spaces, biographies, social networks and their welfare gains and externalities: some hypotheses and empirical results. Mobilities 2(1), 15-36 (2006)

Baron, N.: Adjusting the volume: in-place and mobile dimensions of discourse control through technology. In: Proceedings of Mobile Communication and the Network Society. Rutgers University, USA (2005)

Bird, C.E., Fremont, A.M.: Gender, time use and health. J. Health Soc. Behav. 32(2), 114-129 (1991)

Breusch, T.S.: Maximum likelihood estimation of random effects model. J. Econom. 36, 383-389 (1987)

Carrasco, J.A., Miller, E.J.: Exploring the propensity to perform social activities: social networks approach. Transportation 33, 463-480 (2006)

Carrasco, J.A., Miller, E.J.: The social dimension in action: a multilevel, personal networks model of social activity frequency. Transp. Res. Part A 43(1), 90-104 (2009)

Chikaraishi, M., Fujiwara, A., Zhang, J., Axhausen, K., Zumkeller, D.: Changes in variations of travel time expenditure. Transp. Res. Rec. 2230, 121-131 (2011)

Circella, G., Mokhtarian, P.L., Poff, L.K.: A conceptual typology of multitasking behaviour and polichronicity preferences. Int. J. Time Use Res. 9(1), 59-107 (2012)

Cirillo, C., Axhausen, K.W.: Dynamic model of activity type choice and scheduling. Transportation 37(1), 15-38 (2010). (2012)

Cullen, I.G.: The treatment of time in the explanation of spatial behaviour. In: Carlstein, T., Parkes, D.N., Thrift, N.J. (eds.) Time space and spacing time II: human activity and time geography, pp. 27-38. Edward Arnold, London (1978)

Cullen, I.G., Godson, V.: Urban networks: the structure of activity patterns. Prog. Plan. 4, 1-96 (1975)

Dharmowijoyo, D.B.E., Susilo, Y.O., Karlstöm, A.: Day-to-day inter- and intra-personal variability of individual's activity space in a developing country. Environ. Plann. B 41, 1063-1076 (2014)

Dharmowijoyo, D.B.E., Susilo, Y.O., Karlström, A.: The day-to-day variability in travellers' activity-travel patterns in the Jakarta Metropolitan Area. Transportation (2015a). doi:10.1007/s11116-015-9591-4

Dharmowijoyo, D.B.E., Susilo, Y.O., Karlstöm, A.: Collecting a multidimensional three-weeks household time-use and activity diary in the Bandung Metropolitan Area. Transp. Res. Part A 80, 231-246 (2015b) 
Dharmowijoyo, D.B.E., Susilo, Y.O., Karlstöm, A.: Relationships among activity duration, travel time spent and activity space indices in the Jakarta Metropolitan Area, Indonesia. J. Transp. Geogr. 54, 148-160 (2016a)

Dharmowijoyo, D.B.E., Susilo, Y.O., Karlstöm, A.: Analysing the complexity of day-to-day an individual's activity-travel pattern using multi-dimensional sequence alignment method: a case study in Bandung Metropolitan Area. Indonesia. In: Accepted for Presentation at the 95th Annual Meeting of the Transport Research Board (2016b)

Dijst, M., Farag, S., Schwanen, T.: A comparative study of attitude theory and other theoretical models for understanding travel behaviour. Environ. Plan. A 40, 831-847 (2008)

Dijst, M., Rietveld, P., Steg, L.: Individual needs, opportunities and travel behaviour: a multidisciplinary perspective based on psychology, economics and geography. In: Wee, B., Annema, J.A., Banister, D. (eds.) The Transport System and Transport Policy, pp. 19-50. Edward Elgar Publishing, Massachusetts (2009)

Gärling, T., Axhausen, K.W.: Introduction: habitual travel choice. Transportation 30, 1-11 (2003)

Gärling, T., Fujii, S., Boe, O.: Empirical test of a model of determinants of script-based driving choice. Transp. Res. Part F 4, 89-102 (2001)

Golledge, R.G., Stimson, R.J.: Spatial Behaviour. The Guilford Press, New York (1997)

Greene, W.: Econometric Analysis. Prentice Hall, New Jersey (1993)

Gujarati, D.: Basic Econometric. McGrawHill, Boston (2003)

Hägerstrand, T.: What about people in regional sciences? Reg. Sci. Assoc. 247(21), 7-21 (1970)

Handy, S., Cao, X., Mokhtarian, P.: Correlation or causality between the built environment and travel behavior? evidence from Northern California. Transp. Res. Part D 10, 427-444 (2005)

Hansen, C.B.: Inference in linier panel data models with serial correlation and an essay on the impact of 401(k) participation on the wealth distribution. Ph.D. Dissertation. Massachusetts Institute of Technology (2004)

Heinen, E., Chatterjee, K.: The same mode again? exploration of mode choice variability in Great Britain using the National Travel Survey. Transp. Res. Part A 78, 266-282 (2015)

Hunt, E., McKay, E.A., Dahly, D.L., Fitzgerald, A.P., Perry, I.J.: A person-centred analysis of the time use, daily activities, and health related quality of life of Irish school-going late adolescent. Qual. Life Res. 24, 1303-1315 (2015)

Joewono, T.B., Kubota, H.: User perception of private paratransit operation in Indonesia. J. Public Transp. 10(4), 99-118 (2007a)

Joewono, T.B., Kubota, H.: User satisfaction with paratransit in competition with motorization in Indonesia: anticipation of future implications. Transportation 34(3), 337-354 (2007b)

Joh, C.H., Arentze, T., Hofman, F., Timmermans, H.J.P.: Activity pattern similarity: a multidimensional alignment method. Transp. Res. Part B 36, 385-403 (2002)

Kang, H., Scott, D.M.: Exploring day-to-day variability in time use for household members. Transp. Res. Part A 44, 609-619 (2010)

Kang, H., Scott, D.M., Doherty, S.T.: An investigation of planning priority of joint activities in the household activity scheduling process. Transp. Res. Rec. 2134, 82-88 (2009)

Kenyon, S.: What do we mean by multitasking? exploring the need for methodological clarification in timeuse research. Int. J. Time Use Res. 7(1), 609-619 (2010)

Kenyon, S., Lyons, G.: Introducing multitasking to the study of travel and ICT. Transp. Res. Part A 41, 161-175 (2007)

Lee, Y., Hickman, M., Washington, S.: Household type and structure, time use pattern, and trip chaining behaviour. Transp. Res. Part A 41, 1004-1020 (2007)

Lewin, K.: Principles of topological psychology. McGraw-Hill, New York (1936)

Marion, R.: The Edge of Organization: Chaos and Complexity Theories of Formal Social Systems. Sage, Thousand Oaks (1999)

McCarthy, P.: Understanding slumps: case studies for the global report on human settlements. World Bank (2003)

McDonald, W.J.: Time use in shopping: the role of personal characteristics. J. Retail. 70(4), 345-365 (1994)

Meloni, I., Guala, L., Loddo, A.: Time allocation to discretionary in-home, out-of-home and to trips. Transportation 31, 69-96 (2004)

Miller, H.J.: A measurement theory for time geography. Geograph. Anal. 37, 17-45 (2005)

Moiseeva, A., Timmermans, H.J.P., Choi, J., Joh, C.H.: Sequence alignment analysis of activity-travel pattern's variability using eight weeks' diary data. Transp. Res. Rec. 2412, 49-56 (2014)

Paccione, M.: Urban environment quality and human wellbeing-a social geographical perspective. Landsc. Urban Plan. 65, 19-30 (2003) 
Pendyala, R.M., Yamamoto, T., Kitamura, R.: On the formulation of time-space prisms to model constraints on personal activity-travel engagement. Transportation 29, 73-94 (2002)

Perugini, M., Bagozzi, R.P.: The role of desires and anticipated emotions in goal-directed behaviours: broadening and deepening the theory of planned behaviour. Br. J. Soc. Psychol. 40, 79-98 (2001)

Perugini, M., Conner, M.: Predicting and understanding behavioural volitions: the interplay between goal and behaviours. Eur. J. Soc. Psychol. 30, 705-731 (2000)

Putnam, R.D.: Bowling Alone: The Collapse and Revival of American Community. Simon and Schuster, New York (2001)

Ramalingam, B., Jones, H., Reba, T., Young, J.: Exploring the science of complexity: ideas and implications for development and humanitarian efforts. Working Paper 285, Results of ODI Research (2008)

Rasouli, S., Timmermans, H.: Judgements of travel experiences, activity envelopes, trip features and multitasking: a panel effects regression model specification. Transp. Res. Part A 63, 65-75 (2014)

Raux, C., Ma, T.Y., Cornelis, E.: Variability and anchoring points in weekly activity-travel patterns. In: Transportation Research Board 91st Annual Meeting, Washington (2012)

Schlich, R., Axhausen, K.W.: Habitual travel behaviour: evidence from a six-week diary. Transportation 30(1), 13-36 (2003)

Schwanen, T., Kwan, M.P., Ren, F.: How fixed is fixed? gendered rigidity of space-time constraints and geographies of everyday activities. Geoforum 39, 2109-2121 (2008)

Snijders, T.A.B., Bosker, A.J.: Multilevel Analysis: An Introduction to Basic and Advanced Multilevel Modelling. Sage, London (1999)

Stauffacher, M., Schlich, R., Axhausen, K.W., Scholz, R.W.: The diversity of travel behaviour: motives and social interactions in leisure time activities. Arbeitsberichte Verkehr-und Raumplanung. 30x. IVT. ETH Zürich, Zürich (2005). http://www.ivt.ethz.ch/vpl/publications/reports/ab328.pdf

Sullivan, O., Gershuny, J.: Domestic outsourcing and multitasking: how much do they really contribute? Sociology Working Papers, Department of Sociology, University of Oxford (2012)

Susilo, Y.O.: Paratransit. In: Button, K., Nijkamp, P., Vega, H. (eds.) A Dictionary of Transport Analysis. Edward Elgar Publishing, Cheltenham (2011)

Susilo, Y.O., Avineri, A.: The impacts of household structure to the day-to-day variability of individual and household stochastic travel time budget. J. Adv. Transp. 48, 454-470 (2014)

Susilo, Y.O., Axhausen, K.W.: Stability in individual daily activity-travel-location patterns: a study using the Herfindahl-Hirschman Index. Transportation 41, 995-1011 (2014)

Susilo, Y.O., Liu, C.: Examining the relationships between individual's travel, in-home and out-of-home activities and their physical, mental and social health indicators: case study in the Bandung Metropolitan Area, Indonesia. In: Paper Submitted to the World Conference on Transport Research, Shanghai (2016)

Susilo, Y.O., Joewono, T.B., Santosa, W.: An exploration of public transport users' attitudes and preferences towards various policies in Indonesia. J. East. Asia Soc. Transp. Stud. 8, 1202-1216 (2010)

Susilo, Y.O., Hanks, N., Ullah, M.: An exploration of shoppers travel mode choice in visiting convenience stores in the UK. J. Transp. Plan. Technol. 36(8), 669-684 (2013)

Susilo, Y.O., Joewono, T.B., Vandebona, U.: Investigating the reasons underlie repetitive traffic violations behaviours among motorcyclists. J. Accid. Anal. Prev 75, 272-284 (2015)

Suzukamo, Y., Fukuhara, S., Green, J., Kosinski, M., Gandek, B., Ware, J.E.: Validation testing of threecomponent model of short form-36 scores. J. Clin. Epidemiol. 64, 301-308 (2011)

Tarigan, A.K., Susilo, Y.O., Joewono, T.B.: Segmentation of paratransit users based on service quality and travel behaviour in Bandung, Indonesia. J. Transp. Plan. Technol. 37(2), 200-218 (2014)

Tarigan, A.K., Sagala, S., Samsura, D.A.A., Fisabilillah, D.F., Simarmata, H.A., Nababan, M.: Bandung City, Indonesia. Cities 50, 100-110 (2016)

Thomson, J.A., Shaw, D., Shiu, E.: An empirical examination of goal desire and emotion in the context of smoking cessation. ANZMAC, 1-8 (2009)

Urry, J.: The complexities of global. Theory Cult. Soc. 22(5), 235-254 (2005)

Van Acker, V., Wee, B., Witlox, F.: When transport geography meets social psychology: toward a conceptual model of travel behaviour. Transp. Rev. 37(2), 219-240 (2011)

Weick, K.: Education organizations as loosely coupled systems. Adm. Sci. Q. 21, 1-9 (1976)

Yamamoto, T., Kitamura, R.: An analysis of time allocation to in-home and out-of-home discretionary activities across working days and non-working days. Transportation 26, 211-230 (1999)

Zhang, J: Urban forms and health promotion: an evaluation based on health-related QOL indicators. In: $13^{\text {th }}$ World Conference on Transport Research (WCTR) (2013) 
Dimas B. E. Dharmowijoyo is a lecturer in Civil Engineering of Institute of Technology and Science, Bandung, Indonesia. He is investigating the complexity of individuals' everyday mobility. He is trying to figure out how multi-dimensional factors interconnected and interrelated with each other in shaping the complexity of individuals' decision making process and activity-travel patterns, thus influence transport and urban planning, and policy.

Yusak O. Susilo is an Associate Professor in Transport Analysis and Policy at the KTH Royal Institute of Technology. Sweden. His main research interest lies in the intersection between transport and urban planning, transport policy, decision making processes and behavioural interactions modelling.

Anders Karlström is a Professor in Transport and Economics at the KTH Royal Institute of Technology. Sweden. His research interests include transport analysis and planning, behavioural economics, discrete choice and econometrics. 